\title{
WAYANG DAN NILAI- NILAI ETIS: SEBUAH GAMBARAN SIKAP HIDUP ORANG JAWA
}

\author{
Selu Margaretha Kushendrawati
}

\begin{abstract}
The Javanese wayang performance reflects some ethical values that express the attitudes and norms of the Javanese people. The wayang stories bring into focus some elements of the culture, such as customs, arts, way of life, mysticism, and religion. The characters of the wayang performance depict some ways of life and mind-sets of the Javanese of an understanding of the final destination of life, sangkan paraning dumadi, which is a longing to be united with God at the end of their life. Wayang performance is a high form of Javanese culture that needs to be preserved to sustain multiculturalism in Indonesia.
\end{abstract}

\section{Keywords}

Wayang, ethical values, way of life.

\begin{abstract}
Abstrak
Wayang sebagai kebudayaan Jawa merupakan nilai- nilai etis yang menggambarkan sikap hidup orang Jawa. Dalam wayang termuat unsur- unsur kebudayaan seperti customs, art, way of life, mystic and religion. Melalui tokoh- tokoh dalam pewayangan dapat teranalogikan aneka ragam cara hidup maupun cara pikir manusia Jawa di mana manusia Jawa tidak dapat dipisahkan dengan tujuan hidupnya "sangkan paraning dumadi". Wayang merupakan kebudayaan Jawa adiluhung yang perlu dilestarikan demi keutuhan multikulturalisme di Indonesia.
\end{abstract}

\section{Kata kunci}

Wayang, nilai etis, way of life.

\section{PENGANTAR}

Bangsa Indonesia khususnya masyarakat Jawa, dalam pencarian nilai-nilai luhur yang terkandung dalam berbagai sumber kebudayaannya antara lain terdapat dalam contoh-contoh pewayangan. Wayang dalam masing-masing penokohannya dapat dikatakan merupakan gambaran kehidupan konkret orang Jawa. Seluruh pengejawantahan wayang tampak jelas dapat diartikan sebagai suatu konsep filosofis etis yang diekspresikan dalam suatu karya seni estetis yang tinggi.

Membicarakan wayang dari segi etis berarti membicarakannya melalui bidang studi filsafat karena etika adalah merupakan salah satu bidang filsafat di antara bidang- 
bidang lain seperti ontologi, epistemologi, dan axiologi di mana estetika dan etika berada di dalamnya. Etika adalah bidang studi terpraktis filsafat yang membicarakan apa itu yang baik dan apa yang buruk secara normatif-spekulatif. Dalam hal ini penulis melihat adanya nilai- nilai etis dalam wayang yang walaupun normatif namun luwes, dinamis dan kritis sebagai gambaran sikap hidup orang Jawa. Wayang dapat diidentifikasikan dengan kontekstualisasi kehidupan manusia Jawa pada umumnya, bahkan wayang juga merupakan pemberi makna melalui teks-teks yang dilantunkan dalam cerita-ceritanya.

Seperti yang kita ketahui manusia adalah pencipta kebudayaan, maka segala sesuatu yang diciptakan dengan rasa, karsa manusia dapat dipahami sebagai kebudayaan. Demikian juga dengan wayang, wayang adalah kebudayaan, walaupun tidak berasal-muasal sepenuhnya dari Indonesia, tetapi berdasarkan cipta, rasa dan karsa orang Indonesia pada umumnya dan orang Jawa khususnya maka wayang menjadi salah satu khas Jawa. Lalu timbul pertanyaan yang mendasar siapa sebenarnya manusia Jawa dan bagaimana perilaku atau sikap manusia Jawa ditandai? Mengapa manusia Jawa dapat dikatakan bergambar atau bercermin pada nilai-nilai etis dalam wayang? Berbicara mengenai manusia Jawa dapat ditinjau dari berbagai aspek kebudayaan seperti adat istiadat (customs), seni (art), cara hidup (way of life), mistik dan agama (mystic and religion) dan lain- lain.

Tulisan ini memaparkan bagaimana nilai-nilai etis dalam wayang melalui tokohtokoh Mahabharata antara lain seperti Harjuna, Karna, Kresna, Duryudana, Samiaji, Drupadi dan tokoh-tokoh Ramayana seperti Hanoman, Kumbakarna dan lain-lainnya. Norma-norma etis pada tokoh-tokoh tersebut banyak yang dapat dianalogikan dan disamakan dengan konsep kehidupan orang Jawa. Juga tak mungkin tidak tersinggung didalamnya masalah konsep filosofis sikap dan pandangan hidup manusia atau orang Jawa sebagai sisi keseimbangan dari sisi praktis pragmatis etis.

\section{FILSAFAT JAWA SEBAGAI PENCARIAN JATI DIRI}

Studi filsafat adalah studi tentang kemanusiaan dengan segala kemampuankemampuannya secara menyeluruh dan bersifat akali. Selain itu kita juga mengetahui bahwa kebudayaan adalah merupakan hasil ekspresi manusia baik yang bersifat jasmaniah maupun rohaniah. Oleh karenanya filsafat merupakan hasil studi rasio manusia yang sekaligus dapat dikategorikan sebagai kebudayaan. Dengan demikian

filsafat Jawa berarti mempelajari kemampuan-kemampuan manusia Jawa dalam menciptakan kebudayaannya secara luas dan mendasar dan hakiki.

Di dalam kehidupan rohani yang merupakan dasar dan pemberi isi kebudayaan Jawa, manusia Jawa benar- benar berusaha dengan gigih dalam pencarian prinsip- dasar segala sesuatu. Sikap hidup orang Jawa selalu ingin merefleksi tentang apa yang terdapat di balik segala wujud inderawi serta pencarian sebab-sebab terdalam daripadanya yaitu sangkan paraning dumadi. Untuk mencari tujuan akhir dari setiap manusia terdapat suatu 
perjalanan yang panjang di mana manusia harus mengetahui dan meniti apa arti hidupnya, asalmula dan akhir kehidupannya. Untuk itu manusia harus menjalin hubungan baik antara manusia dengan Tuhan, manusia dengan sesama dan manusia dengan alam (Ciptoprawiro 1986: 11). Artinya, manusia harus menjalani hubungan baik secara horisontal maupun vertikal, ada bersama sesama dan ada bersama Yang Abadi yaitu Tuhan.

Tokoh Bima dalam Dewa Ruci merupakan sebuah contoh orang Jawa yang mencari air hidup atau hakikat diri dan memperoleh wirid dalam ilmu sejati dalam dirinya. Ia berhasil menemukan dirinya dalam dirinya sendiri (Dwiyanto 2010: 54). Contoh tersebut menunjukkan betapa usaha Bima merupakan hal yang memang telah berakar dalam kehidupan manusia Jawa yang senantiasa

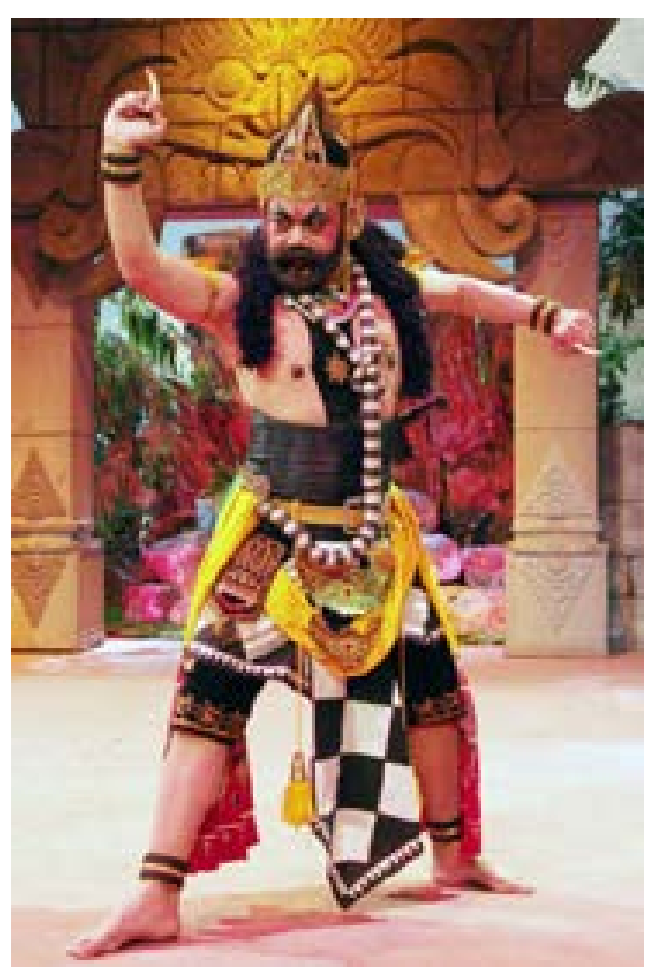

Gambar 1. Bima tak dapat terlepas dari pendekatan-pendekatan mistisisme. Dalam hal ini tampak perbedaan menyolok antara sistem filsafat Barat dan sistem filsafat Jawa. Filsafat Jawa cenderung bertendensi kepada filsafat Timur yang selalu menekankan sikap-sikap harmoni. Filsafat Timur tidak menciptakan filsafat untuk filsafat sendiri seperti Filsafat Barat melainkan filsafat hanyalah pengetahuan yang merupakan sarana untuk mencapai kesempurnaan melalui satu-satunya jalan bagi manusia untuk sampai kepada tujuan akhir yang disebut 'manunggaling kawula Gusti' (mystical union). Tinjauan atas teori-teori tentang perbandingan Timur-Barat menunjukkan keanekaragaman yang luas dan juga memberikan beberapa wawasan yang mendalam.

Bagi manusia Jawa, pengkajian kebenaran tidak semata-mata berdasarkan rasio seperti pada filsafat Barat pada umumnya, melainkan sekaligus melalui 'lelaku' (tapa brata) dan pendalaman indera batin. Rasio dan indera batin dalam konsep Jawa dapat disamakan dengan cipta dan rasa. Seringkali indera batin ini lebih mengedepan daripada rasio sehingga indera batin menduduki peran yang lebih utama dibanding dengan rasio. Maka tidak mengherankan apabila filsafat Jawa atau lebih tepatnya konsep atau pandangan hidup manusia Jawa dianggap irasional dan lebih dekat dengan alam yang berada di luar akal yaitu dunia mistik.

Mistik dari kata Yunani mustikos merupakan warna tersendiri bagi kebudayaan dan sikap hidup manusia Jawa sejak jaman dahulu (Haryanto 1992: 161). Sampai saat inipun mistik masih ada bahkan berkembang dan mendorong banyak orang bersandar kembali padanya akibat ketidakpastian yang melanda kehidupan dewasa ini. Seperti 
yang kita saksikan, ketidakpastian dan kegoncangan jiwa masyarakat semakin besar terutama bagi masyarakat yang hidup di tengah-tengah kota besar. Selain itu berbagai keresahan yang ditimbulkan kelompok-kelompok agama yang seringkali menganggap bentuk-bentuk kepercayaan sebagai sisi- sisi lain dari agama. Seringkali terjadi pertikaian karena ketidaksepahaman antar masyarakat dan kelompok-kelompok masayarakat. Bagi manusia Jawa perbedaan-perbedaan religi tidak begitu dipermasalahkan asalkan tetap dalam berketuhanan. Maka semakin agama-agama memperuncing fanatisme, eksklusivisme dogma-dogmanya, semakin bermunculanlah aliran-aliran baru yang tak lain merupakan sikap pembelaan terhadap sebuah hak kemanusiaan.

Lagi-lagi di sini tampak jelas perbedaan antara konsep pemikiran Barat dan konsep pemikiran Jawa. Filsafat Barat secara tegas memisahkan antara filsafat dan mistik. Filsafat semata-mata merupakan kemampuan akal budi manusia sehingga filsafat haruslah rasional, sementara mistik berada di dalam ruang lingkup religi yang bermodalkan keyakinan dan kepercayaan. Oleh karenanya mistik terdapat dalam ruang lingkup agama atau lebih tepatnya religi (kepercayaan dalam arti yang luas). Khusus dalam konteks kejawen pengertian filsafat telah diartikan secara implisit ke dalam konsep kemistikan di mana hal tersebut mengimplementasi dalam kehidupan manusia Jawa. Maka kalau dunia mempostulatkan bahwa filsafat itu lahir sejak bergesernya mitos ke logos di Yunani pada abad ke 5 SM (Bertens 1991: 18), di sisi lain berarti dapat dikatakan Filsafat Jawa merupakan $a$ way of life bagi orang Jawa dalam pencarian jati dirinya, sangkan paraning dumadi (Sardjono 1992: 24). Filsafat Jawa adalah pemikiran yang bukan hanya konseptual melainkan lebih menonjolkan pendekatan praksis, menghendaki setiap orang mau melakukannya dan menjadikannya sebagai sikap hidup sehari-hari. Inilah perbedaan pemikiran Barat dengan pemikiran Timur khususnya Jawa.

\section{WAYANG DAN NORMA ETIS}

Sebenarnya wayang memang tidak dikenal hanya oleh orang Jawa saja, walaupun menurut seorang pakar dari Barat bernama Brandes mengatakan bahwa wayang merupakan khas Jawa (Amir 1991: 26). Seperti telah dikemukakan di atas, orang Jawa mengenal dunia pewayangan. Bahkan bisa diklaim, dunia pewayangan adalah dunia dan kebudayaan khas manusia Jawa karena wayang dengan tokoh-tokohnya merupakan gambaran kehidupan beserta norma-norma etis dengan seluruh multidimensionalnya manusia Jawa. Wayang juga merupakan gambaran kehidupan manusia konkret dengan segala sifat karakter-karakter unik yang ada pada aneka ragam manusia individual, partikular. Kehalusan batin yang terwujud dalam perilaku bijaksana ataupun perilaku angkara murka dari kecantikan batin dapat terungkap dan tercermin dalam tokohtokoh pewayangan Jawa.

Maka membicarakan wayang berarti membicarakan manusia atau masyarakat Jawa. Dalam cerita Mahabharata contohnya, para Kurawa dilambangkan sebagai 
kekuatan angkara murka sedangkan di pihak lain Pandawa selalu merupakan cerminan kekuatan sifat-sifat luhur, adil, baik dan semacamnya.

Seperti yang umum ketahui, cerita wayang seperti epos Mahabharata dan Ramayana sebenarnya berasal dari India. Namun melalui semacam inisiasi maka cerita-cerita wayang mengalami perubahan dan menjadi kebudayaan khas Indonesia khususnya Jawa di samping ada bermacam-macam bentuk wayang seperti wayang golek, wayang orang, wayang potehi, wayang Krucil dan lain-lainnya. Tetapi bentuk yang paling populer di Jawa adalah wayang kulit. Lakon-lakon wayang kulit diambil dari cerita klasik wayang purwa. Sedangkan lakon-lakon wayang purwa sebagian besar diambil dari bahan-bahan cerita yang berasal dari cerita- cerita epos Mahabharata, Ramayana ataupun sempalan-sempalan dari keduanya melalui kontekstualisasi menjadi seperti yang sekarang kita saksikan. Oleh karenanya, epos seperti Mahabharata, Ramayana yang berasal dari India seperti dalam kenyataannya jelas tampak perbedaan yang mendasar dalam perwujudannya dengan di Indonesia. Bagi masyarakat Jawa cerita-cerita wayang menyimbolkan perilaku dan watak manusia dalam mencapai tujuan hidup baik lahir maupun batinnya.

Dalam pergelaran wayang, penonton dapat mengenal ajaran-ajaran etis mengenai apa yang baik dan apa yang buruk. Tindakan dari masing-masing tokoh wayang dalam lakon-lakon tertentu seringkali dipakai oleh orang-orang Jawa untuk memahami makna kehidupan ataupun berbagai realitas konkret. Pergelaran wayang terutama wayang kulit selalu sarat dengan misi-misi tertentu, nilai-nilai moral yang esensial seperti hubungan kasih sayang antara orang tua dengan anak, setia negara, tanggung jawab terhadap lingkungan, dan lain-lain. Sebagai contoh, hal itu diilustrasikan dalam episode .'Karna gugur', ketika dewi Kunti menangis dan melarang Karna putranya untuk tidak pergi ke medan Kurusetra melawan adiknya sendiri yaitu Harjuna. Karena apabila Karna berperang melawan Harjuna pasti ia akan kalah. Namun permintaan ibundanya tersebut ditolak karena Karna setia kepada Duryudana (yang walaupun Duryudana adalah tokoh antagonis) yang telah memberinya kesejahteraan dan kelayakan hidup sementara sang ibu sendiri telah membuangnya karena malu mempunyai anak hasil selingkuh dengan dewa Surya dan saudara-saudaranya sendiri/ Pandawa juga mencampakkannya. Dalam cerita tersebut dapat dipetik makna sebuah loyalitas, rasa setia terhadap negara dari seorang Karna yang rasional riil. Dalam hal ini Karna secara tegas dapat menunjukkan suatu kepribadian etis terhadap kebaikan budi Duryudana terlepas Duryudana adalah musuh ibu dan saudara-saudaranya sendiri.

Prabu Samiaji atau Puntadewa atau Yudhistira adalah si sulung Pandawa yang selalu diidentifikasikan sebagai orang yang jujur, baik hati, adil dan berhati suci, lambang manusia sempurna. Namun walau demikian demi negara dan kemenangan dari kelicikan pendeta Dorna iapun pernah melakukan kebohongan dengan terpaksa. Untuk mengalahkan mental pendeta Dorna ia berbohong. Ketika Sang Pendeta yang 
juga merupakan guru para Pandawa dan juga para Kurawa ini diangkat oleh Duryudana menjadi senapati di medan Kurusetra dalam perang Bharatayuda Jayabinangun, serentak para Pandawa terhenyak. Pandawa mengetahui betapa sulitnya mengalahkan Sang Guru yang sakti itu. Sri Kresna sebagai penasihat Pandawa mengusulkan suatu ide bahwa Dorna hanya akan terguncang konsentrasinya apabila ia mendengar kabar buruk tentang anak satu- satunya yaitu Aswatama. Namun Dorna tak mudah percaya berbagai provokasi yang menjatuhkan mentalnya. Oleh karena itu perlu orang yang dapat dipercaya keadilan dan kejujurannya yaitu Samiaji. Maka ketika di medan Kurusetra terdengar gegap gempita teriakan "Aswatama mati, Aswatama mati!" Dornapun terkesiap dan segara mencari Samiaji "Apa benar Aswatama mati?" dan dijawab oleh Samiaji "Ya benar Aswatama telah mati" serta ditambah dengan nada lirih nyaris tak terdengar "tetapi Aswatama gajah". Begitulah sebuah tanggung jawab moral dari seorang raja seperti Samiaji, berani berbohong demi negara dan rakyatnya, walaupun ia sebenarnya sangat menghormati Dorna sebagai guru yang telah banyak mengajarkan pengetahuan padanya. Konon yang empunya cerita mengilustrasikan, begitu Samiaji mengucapkan kebohongannya maka seketika itu juga roda kereta perang yang ditungganginya turun menyentuh tanah, sejak itu Samiaji tidak lagi diidentifikasikan sebagai orang yang sempurna. Artinya, sebenarnya tidak ada manusia sempurna di dunia ini.

Harjuna si penengah Pandawa yang diilustrasikan sebagai ksatria tampan, banyak didekati kaum perempuan, sakti mandraguna, gemar bertapa dan disayang oleh para dewa. Dalam cerita "Karna gugur" sempat Harjuna mengalami kebimbangan yang luar biasa karena yang akan dihadapinya adalah saudaranya sendiri yaitu Karna Surya Atmaja alias Karna anak Batara Surya dengan ibunda Harjuna Dewi Kunti. Harjuna juga mengetahui bahwa Karna memiliki senjata ampuh bak rudal yang tak kenal meleset yaitu Konta. Dalam hal ini kembali Sri Kresna turut campur dan membuat skenario untuk menyiasati Konta agar tak tertuju pada Harjuna. Untuk itu (dalam cerita "Gatotkaca perlaya") sengaja diperintahkan kepada Gatotkaca putra Bima itu untuk memancing emosi kemarahan Karna di medan Kurusetra agar Karna melepas Konta kepadanya. Itulah yang terjadi dan gugurlah Gatotkaca sebagai pahlawan bangsa, rela berkorban demi pamannya yang dianggap lebih berharga daripada dirinya.

Dengan demikian Harjuna telah aman dari senjata Konta, karena Konta hanya dapat dipakai satu kali saja. Harjuna menderu, melesat dengan kereta perangnya menuju medan Kurusetra bersama sais istimewanya sekaligus penasihat dan pengatur lakunya yaitu Sri Kresna. Dalam kereta itu Kresna tak berhenti-berhentinya memberi nasihat dan memberi perintah Harjuna apa yang harus dilakukan dan apa yang tidak harus ia lakukan. Harjuna sempat ragu ketika ia harus membidikkan Pasupati kepada Karna yang saudara tuanya sendiri. Namun atas desakan dan penjelasan-penjelasan yang mantap dari Kresna akhirnya tanpa ragu Harjuna melepaskan senjata andalannya dan gugurlah Karna. Dari episode tersebut jelas-jelas tergambarkan bahwa Harjuna 
walaupun seorang ksatria unggulan tiada duanya namun tetap memiliki kemanusiaan dan kasih sayang yang besar, walau demikian ia dapat membedakan antara masalah pribadi dengan tugas negara, ia menyadari kewajibannya.

Sri Kresna yang dikenal sebagai titisan dewa Wisnu adalah seorang raja terpandang saudara para Pandawa dan Kurawa. Seperti diketahui Kurawa dan Pandawa adalah saling bersaudara, dengan demikian Kresna pun adalah saudara dari dua kubu tersebut. Namun di sana telah terdapat sebuah contoh tentang ketidakadilan karena Kresna selalu menjadi pembela pihak Pandawa termasuk seringkalinya ia melakukan provokasiprovokasi demi kemenangan Pandawa. Hal tersebut dapat dengan jelas didapati pada hampir seluruh episode pergelaran wayang di mana

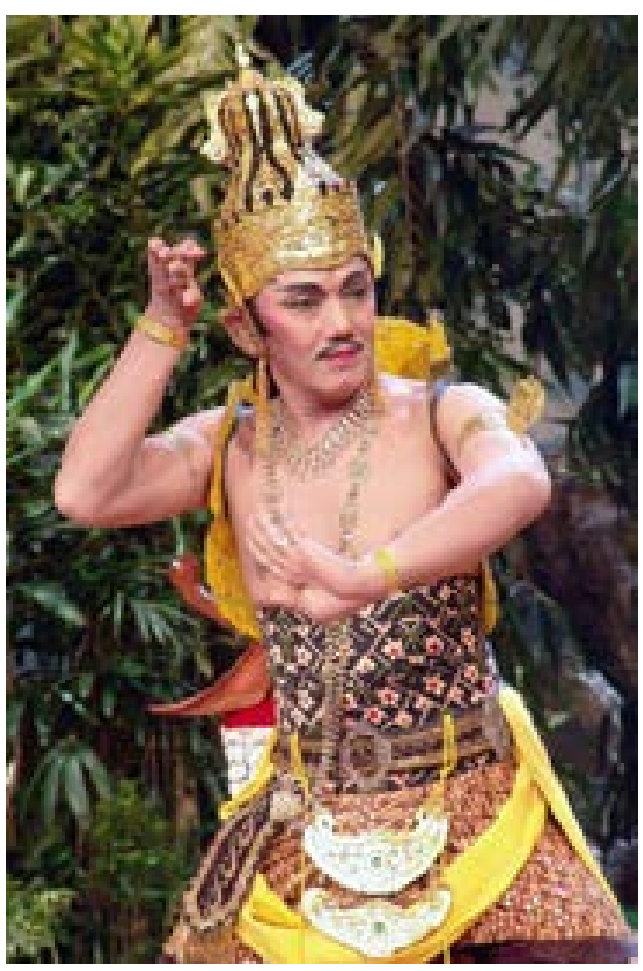

Gambar 2. Kresna Kresna selalu berada untuk intervensi dalam segala penyelesaian masalah. Kresna tak segan-segan melanggar norma-norma etis apabila diperlukan demi pembelaannya untuk para Pandawa. Contoh dalam kasus pengelabuan pada Dorna tentang kematian Aswatama, tentang dikorbankannya Gatotkaca untuk Harjuna, Bambang Ekalaya salah satu murid Dorna yang harus memotong ibu jarinya supaya tak dapat menyaingi Harjuna sebagai pemanah yang handal, tentang Harjuna dan Karna yang saling membunuh. Semua itu suratan dewa yang menugasinya untuk menghancurkan Kurawa. Akibatnya Kresna mendapat karmanya sendiri, ia mati dengan cara yang mengenaskan.

Konon akhir cerita Mahabharata diilustrasikan dengan tragis bahwasanya seluruh Pandawa ditambah Drupadi bersama-sama mendaki gunung Himalaya untuk mencari kesadaran pribadi dan bertemu dengan galih dari Sang Rasajati. Namun sesuai dengan karma masing-masing akhirnya satu persatu mereka menghembuskan nafas terakhir kecuali Samiaji atau Puntadewa beserta seekor anjingnya yang kemudian anjing itu berubah ujud menjadi dewa Darma pelindung Samiaji. Mula-mula Drupadi jatuh tersungkur dan di dikaki gunung Himalaya, ia tewas. Karena menurut si empunya cerita Drupadi ini kurang tulus. Secara fakta ia isteri Samiaji, namun sebenarnya ia lebih mencintai Harjuna.

Kemudian Nakula-Sadewa menysusul karena mereka berdua selalu merasa paling tampan di antara saudara-saudaranya. Setelah itu sang penengah Pandawa pun menghembuskan nafas terakhirnya karena ia pun tak luput dari berbagai kekhilafan, ingin selalu menang dan mendapatkan segala sesuatu dengan cara apapun. Bima alias 


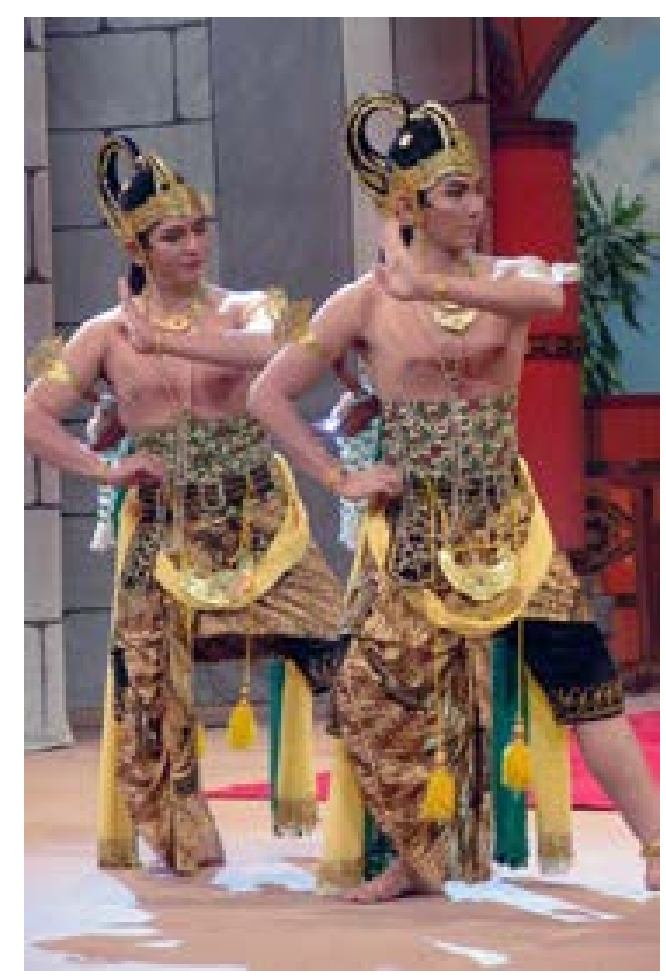

Gambar 3. Nakula dan Sadewa

Werkudarapun tak sampai ke puncak karena ia seringkali hilang kontrol dan kurang peduli perasaan orang lain. Bima adalah seorang ksatria yang tak pernah mampu berbahasa Jawa halus (kromo inggil) yang sepatutnya dibahasakan oleh para priyayi. Maka hanya Samiajilah yang mampu mengenal inti, pusat terdalam dari air kehidupan sehingga hanya ialah yang mencapai kesatuan mistik (mystical union) dalam hidupnya.

Selain epos Mahabharata juga Ramayana. Tokoh Kumbakarna (adik Dasamuka raja Alengkadiraja musuh Sri Rama) adalah sosok tokoh yang seringkali dicontohkan sebagai figur kebaikan, kesetiaan, dan ketaatan yang tulus. Dalam "Gugurnya Kumbakarna" diceritakan bahwa Sinta isteri Rama diculik oleh Dasamuka sehingga terjadilah perang antarnegara. Sampai pada saat tertentu di mana Dasamuka memanggil Kumbakarna untuk bela negara. Walaupun Kumbakarna tahu bahwa Dasamuka di pihak yang salah namun demi membela negara Kumbakarna akhirnya mau turun untuk berperang yang akhirnya ia gugur sebagai ksatria. Dalam paparan cerita gugurnya Kumbakarna tersebut dapat digambarkan nilai etis dari seorang Kumbakarna meskipun ia bertubuh raksasa dan kegemarannya tidur dan makan (dimana sebenarnya ia berbuat seperti itu karena tidak sepihak dengan saudara tuanya Dasamuka yang selalu angkara murka dan bahkan menculik isteri orang dewi Sinta) namun ternyata ia berbudi luhur dan memiliki tanggung jawab moral membela negara sampai titik darah penghabisannya.

Tokoh kera Sugriwa dan Subali dalam Ramayana juga dapat diambil sebagai contoh etis seorang prajurit sejati yang memiliki loyalitas besar terhadap suatu kebenaran. Sugriwa dapat mengambil keputusan dengan penuh kesadaran untuk memihak Sri Rama sang tokoh kebenaran dalam Ramayana. Dengan bantuan Rama akhirnya Sugriwa dapat memenangkan pertandingan antara dirinya dengan saudara tuanya Subali dan gugurlah Subali terkena pusaka Sri Rama.

Hanoman adalah seorang sesepuh yang berada di pihak Sri Rama, ia bertubuh kera putih tetapi berhati mulia dan berpribadi luhur. Dalam "Hanoman Obong" seringkali penonton dibuat terkesima dan tertawa oleh ulah Hanoman yang lucu dan berani yaitu ketika ia membakar Alengkadiraja untuk mengalihkan perhatian Dasamuka agar ia dapat menyampaikan pesan Sri Rama kepada Dewi Sinta. Hanoman, adalah sosok yang ditampilkan dalam kisah Ramayana sebagai simbol kebijaksanaan dan kearifan. Konon sampai saat ini pun Hanoman ini masih ada dan bersemayam di 
salah satu pegunungan di Jawa.

Dari beberapa cerita tersebut yang seringkali dimainkan dalam wayang terutama wayang kulit, maka jelaslah wayang mengandung banyak nilai-nilai etis dan ajaranajaran berperilaku bagi siapapun terutama bagi orang Jawa.

\section{PENUTUP}

Dari apa yang sudah penulis uraikan tentang siapa manusia Jawa, bagaimana sikap hidup orang Jawa serta nilai-nilai etis budaya Jawa dalam hal ini wayang, maka dapat dikatakan bahwa nilai-nilai etis yang terkandung dalam seni wayang merupakan gambaran sikap hidup bagi orang Jawa.

Dari cerita Mahabharata jelas-jelas terurai makna hidup bagi orang Jawa tentang Sangkan Paraning Dumadi, dalam menetapkan ketunggalan segala sesuatu berpangkal pada Yang Satu dan mengembalikan segala sesuatu kepada Yang Satu (dalam Mahabharata hanya Samiajilah manusia sempurna itu). Manusia Jawa selalu mencari tujuan hidupnya melalui askese bahkan mati raga yang tidak lain merupakan usaha mencapai suatu momen peleburan di mana dunia terlebur dalam Tuhan dan Tuhan pun terlebur dalam dunia. Dunia itu sama dengan Ada. Untuk itu perlu norma-norma etis agar tujuan mencapai galih, inti, rasajati terpenuhi.

Socrates, seorang filsuf di abad Yunani kuno (400 SM) berpendapat bahwa tujuan tertinggi setiap manusia adalah mendapatkan Eudaimonia yaitu kebahagiaan yang dalam bahasa Yunani berarti suatu keadaan obyektif yang tidak tergantung pada perasaan subyektif. Dalam pemikiran Ki Ageng Suryomentaram disebut sebagai sebuah kondisi di mana seseorang berada dalam ukuran ke empat. Artinya, seseorang yang mengalami eudaimania atau berada dalam ukuran ke empat adalah orang yang sudah memiliki (paling tidak mendekati) kesempurnaan, memiliki jiwa yang baik, yang sudah merasa cukup dengan dirinya. Untuk itu setiap orang harus memiliki Aretê (istilah Yunani) atau keutamaan, profesionalisme ditambah dengan norma-norma etis yang melekat dan selalu direalisasikan dalam kehidupannya. Dengan demikian niscaya ia akan mengetahui arti kebenaran sejati bukan kebenaran semu.

Terdapat suatu titik temu baik dalam pemikiran Timur (Jawa) maupun Barat (Yunani) di mana pada dasarnya manusia selalu memerlukan nilai- nilai etis dalam kehidupannya. Tampak dalam hal ini bahwa wayang dalam budaya Jawa sarat dengan nilai- nilai sebagai gambaran, cerminan manusia Jawa pada umumnya. Seperti kita ketahui Indonesia memiliki keanakaragaman adat istiadat, cara hidup, bahasa yang sangat multikulturalistik. Maka patutlah jika wayang sebagai kebudayaan Jawa yang adiluhung ini harus dijaga dan dilestarikan dari kepunahannya demi keutuhan Indonesia Raya dari Sabang sampai Merauke. 


\section{DAFTAR BACAAN}

Bertens, Kees. Sejarah Filsafat Yunani. Yogyakarta: Penerbit Kanisius.1991.

Amir, Hazim. Nilai- Nilai Etis dalam Wayang. Jakarta: Pustaka Sinar Harapan. 1991.

Ciptoprawiro, Abdullah. Filsafat Jawa. Jakarta: Balai Pustaka. 1986.

de Jong. Salah satu Sikap Hidup Orang Jawa. Yogyakarta: Penerbit Yayasan Kanisius. 1976.

Dwiyanto, Djoko et.al. Ensiklopedi Wayang, Jogjakarta: Media Abadi. 2010.

Haryanto, S. Bayang-bayang Adiluhung, Filsafat Simbolis dan Mistik dalam Wayang. Semarang: Dahara Prize. 1992.

Mangkunegoro IV, K. G. P. A. A. Terjemahan Wedhatama. Surakarta: Yayasan Mangadeg. 1975.

Magnis-Suseno, Franz. Etika Jawa, Sebuah Analisa Falsafi tentang Kebijaksanaan Hidup Jawa. Jakarta: Gramedia. 1985.

Sarjono, Maria A. Paham Jawa. Jakarta: Pustaka Sinar Harapan. 1992.

Zoetmulder, P. J. Manunggaling Kawula Gusti, Pantheisme dan Monisme. Jakarta: Gramedia. 1991. 